Syndrome of the month

Edited by $D$ Donnai and $R$ Winter

\title{
Hereditary multiple exostoses
}

\author{
Raoul C M Hennekam
}

Hereditary multiple exostoses (HME) is a skeletal disorder which primarily affects enchondral bone during growth. It is characterised by multiple exostoses, usually arising in the juxtaepiphyseal region of the long bones.

Exostoses that affect "almost every bone in the body" were first mentioned by John Hunter in his Lectures on the principles of surgery in $1786 .{ }^{1}$ The first family affected by HME was described by Boyer ${ }^{2}$ in 1814. Virchow ${ }^{3}$ named the disorder multiple exostoses in 1876, and Keith ${ }^{4}$ suggested the name diaphyseal aclasis; this term is still popular in the UK. Several other names have been used in the past and are still used today, including 'osteogenic disease', 'chondral osteogenic dysplasia', 'chondral osteoma', 'dyschondroplasia', 'deforming chondrodysplasia', 'multiple hereditary osteochondromata', 'multiple cartilaginous exostoses', or simply 'exostosis' or 'exostotic dysplasia'.

Papers that were especially important in further delineating the disorder were those of Jaffe, 5 Solomon, ${ }^{6-8}$ and Shapiro et al. ${ }^{9}$ HME may be found not only in man, but also in horse, cattle, dog, cat, lion, and lizard. ${ }^{10}{ }^{11} \mathrm{~A}$ large exostosis was even found on the scapula of a dinosaur. ${ }^{10}$

\section{Incidence}

The frequency of HME is still uncertain. Krooth $e t$ $a l^{12}$ found 21 affected persons among the relatively closed population of the Chamorros of the island of Guam, giving a prevalence of approximately 1 in 1000. Solomon ${ }^{8}$ estimated that three new patients were diagnosed each year at the Royal National Orthopaedic Hospital in London, which handles approximately 7000 new patients annually. Sugiura $e t$ $a l^{13}$ found three to four new cases among the 7000

Clinical Genetics Centre Utrecht, PO Box 18009, 3501 CA Utrecht, The Netherlands. R C M Hennekam annual new patients at the Department of Orthopaedic Surgery in Nagoya. The population prevalence in the UK has been estimated to be 9 per $1000000 .{ }^{14}$ The present author has knowledge of 31 affected living subjects in the population of 2300000 inhabitants who are served by the Clinical Genetics Centre in Utrecht. This may indicate a minimal population prevalence of 13 to 14 per 1000000 . HME is predominantly reported in Caucasians, and to a lesser extent in Orientals, but may be found in other ethnic groups as well. ${ }^{13} 15$

\section{Clinical features}

The diagnosis of HME may be established at birth, but this occurs usually because a specific search is made for it. In most patients the first symptoms arise in childhood: between $65 \%^{7}$ and $89 \%^{15}$ of patients are identified before their sixth year. The first lesion is most often found in the tibia or scapula, probably because they are the most conspicuous sites in the child. ${ }^{7}$ Radiography invariably shows exostoses at other sites as well. The locations of exostoses in HME are tabulated according to their frequency in table 1. Fig 1 shows a severely affected person. Exostoses are rarely found in tarsal and carpal bones and there has only been one patient reported with an exostosis in the skull base $e^{5}$ facial bones always remain free. The number of lesions varies considerably and there may be as many as 80 visible on $x$ rays. The mean number of locations has been found to be $15^{16}$ to $18 .{ }^{15}$ There is no intrafamilial correlation in site or number of exostoses. The family reported by Solomon ${ }^{7}$ with exostoses mainly in the hands and a few in the long bones, and the family with exostoses in the heel only ${ }^{17}$ may well present distinct entities.

HME lesions usually continue to grow until closure of the growth plates at the end of puberty. No new lesions develop thereafter, although regrowth of an exostosis after surgical removal is possible. Spontaneous disappearance of exostoses in childhood or puberty has often been reported. ${ }^{15} 161819$ Some of 
Table 1 Locations of exostoses in HME according to frequency $(n=274) .^{791316}$

\begin{tabular}{lc}
\hline Site & $\%$ \\
\hline Femur, distal end & 90 \\
Tibia, proximal end & 84 \\
Fibula, proximal end & 76 \\
Humerus, proximal end & 72 \\
Femur, proximal end & 66 \\
Tibia, distal end & 64 \\
Ulna, distal end & 61 \\
Radius, distal end & 60 \\
Fibula, distal end & 57 \\
Foot & 35 \\
Scapula & 34 \\
Hand & 33 \\
Rib & 31 \\
Pelvis & 28 \\
Clavicles & 22 \\
Radius, proximal end & 18 \\
Ulna, proximal end & 15 \\
Tarsal bones & 9 \\
Carpal bones & 7 \\
Vertebrae & 7 \\
Humerus, distal end & 5 \\
Sternum & 1 \\
\hline
\end{tabular}

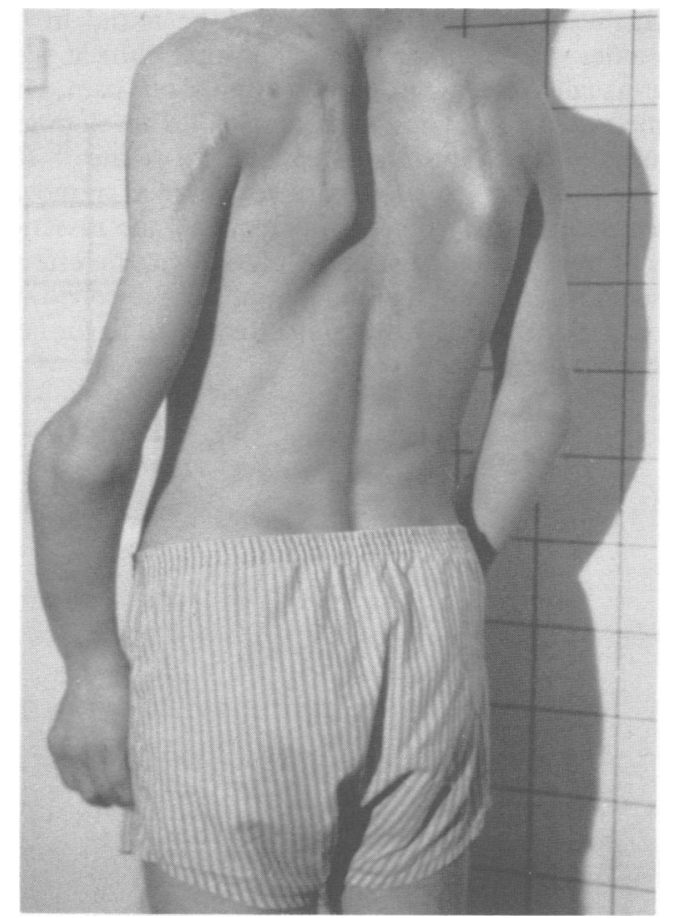

Figure 1 Severely affected adult patient. Note deformed forearms, broad scar formation, and remarkably straight thoracic spine (cf collagen disorders).

these patients may not suffer from HME, but from metachondromatosis, ${ }^{20}$ which is similar to HME but differs in distribution and radiographic appearance, and in which spontaneous regression is the normal course. Another explanation may be ceasing of growth of the exostosis while the affected bone enlarges normally, thus obscuring the once prominent exostotic projection. ${ }^{6}$ A proven disappearance of an exostosis has not been found in any of the patients known to the present author.

The characteristic radiographic appearance of exostoses may vary from broad based (sessile) (fig 2) to pedunculated. The cortex of exostoses is continuous with that of the underlying bone. They originate in the metaphysis in long bones and migrate to the diaphysis as growth continues in the epiphysis. ${ }^{6}$ The cartilagenous cap is usually radiolucent, but after puberty irregular zones of calcification may appear. Extensive calcification with irregularities of the cap should suggest the possibility of malignant change. ${ }^{21}$ The configuration of exostoses may be completely different, not only within different bones of a particular patient, but even within one affected bone. Exostoses prevent normal bone tubulation resulting in metaphyseal widening and growth retardation. Generally, the height of affected persons is somewhat shorter than usual $\left(0.5\right.$ to 1.0 SD). ${ }^{69}$ This becomes more evident with age, especially during puberty. The sitting height averages 1.0 SD above height, indicating a mildly disproportionate short stature. ${ }^{9}$ Comparable findings are reported for arm span and symphyseal height. ${ }^{6}$ The lack of height is seldom so severe that patients fall below the 3rd centile. Sometimes individual bones are more severely

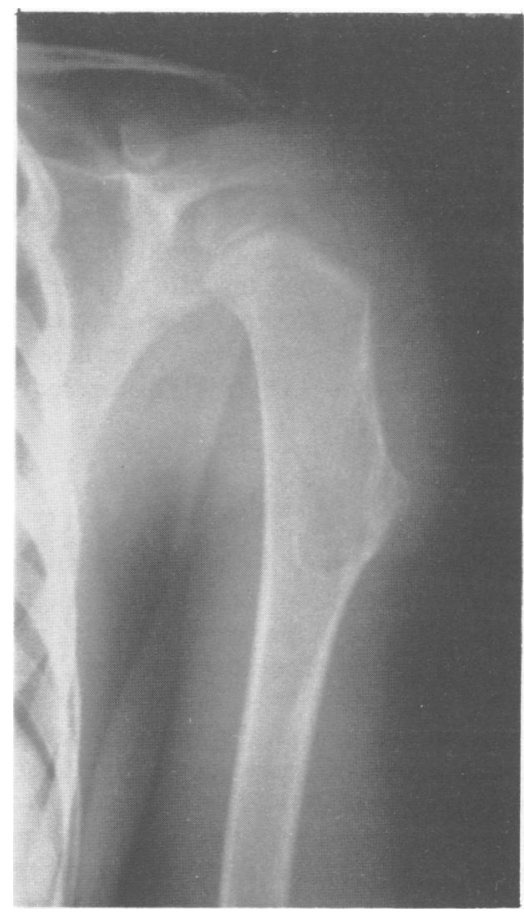

Figure 2 Sessile exostosis at upper end of humerus. 


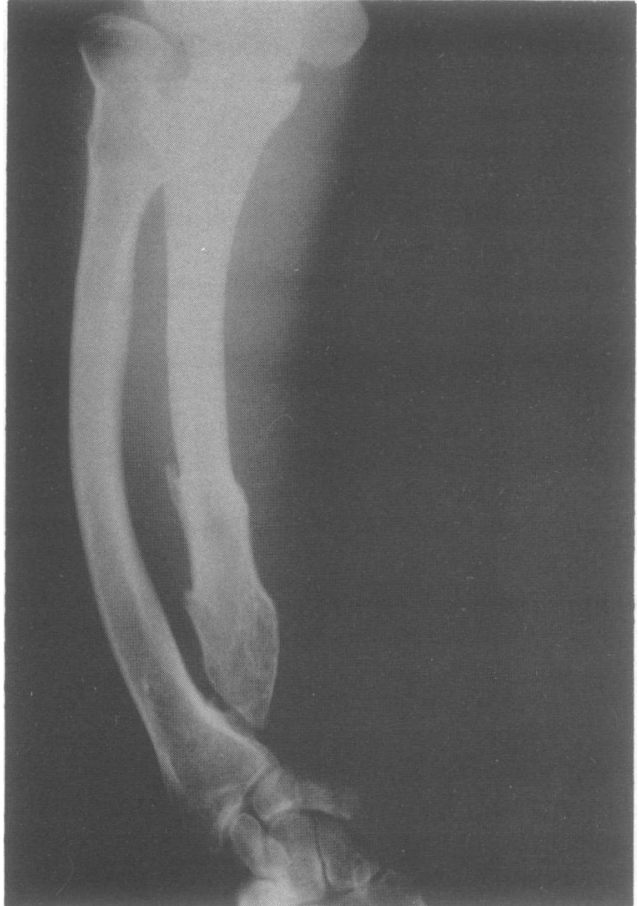

Figure 3 Severely affected forearm.

affected. The most striking deformity may be the shortened and bowed forearm (fig 3). This has been reported in $7 \%,{ }^{13} 40 \%,{ }^{59} 50 \%,{ }^{7}$ and even $60 \%$ of all patients. These differences in incidence may be caused by differences in definitions and groups of patients studied. Exostoses should be removed in patients when they cause disability or for cosmetic reasons, but the mere presence of an exostosis is not a reason for prophylactic excision. A complete review of therapeutic measures in HME has recently been reported by Wood et al. ${ }^{22}$

\section{Complications}

The main complications in HME are hindering of normal articular function, pressure on neighbouring tissues (spinal cord, large blood vessels, peripheral nerves), and malignant degeneration. Impaired movement occurs most often in the elbow (especially pronation) but can be found in nearly every joint.

Vertebral exostoses may cause medullary compression at the cervical or thoracic level. At least 26 such patients have been described, ${ }^{23}$ aged generally between 10 and 40 years. Surgical treatment was of benefit in 21 of them. Compression of peripheral nerves occurs in 1 to $2 \%$ and may cause pain or paraesthesiae. Sometimes a large blood vessel may be involved: at least six persons with HME and a rupture of the popliteal artery have been described. ${ }^{25}$ Occasional other complications are pelvic involvement, causing problems during pregnancy, ${ }^{15}$ and infections of bursae formed between the exostoses and overlying muscles. However, it should be remembered that in the majority of patients exostoses are asymptomatic and interfere little with general health.

The most severe possible complication is malignant degeneration. In some reports about $10 \%$ of all affected persons developed an osteosarcoma. ${ }^{5} 1626$ These figures, however, were obtained at tertiary treatment centres and are, thus, severely biased towards patients with complications. More reliable estimates point to an occurrence of malignancies in HME of 0.5 to $2 \%$. $^{13-15} 21$ Ochsner ${ }^{26}$ collected data on 59 patients with an osteosarcoma in HME. The mean age of onset of malignant degeneration is 31 years; it seldom occurs before the 10th or after the 50th year. The upper end of the femur and the pelvis are the main locations, but they may also be found in the shoulder girdle and the ribs. The first clinical signs are usually a sudden increase in size, pain, and sometimes neurological symptoms. The development is usually slow, and metastasis (lungs) is late. ${ }^{21}$ The therapy of choice is complete surgical removal. Because local recurrences are frequent, the resection has to be complete. Radiation therapy has no effect. ${ }^{7}$ It seems useful to obtain radiographs of the pelvic and shoulder girdle in every young affected adult for later comparison. ${ }^{26}$

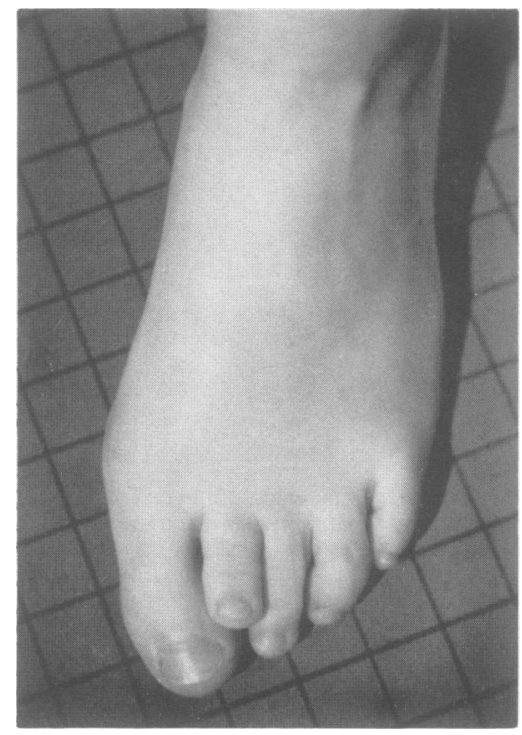

Figure 4 Unilateral shortened second toe; radiography showed exostoses on metacarpal and proximal phalangeal bone. 


\section{Differential diagnosis}

The main differential diagnosis is with trichorhinophalangeal syndrome type II (Langer-Giedion syndrome).$^{27}$ However, the facial, ectodermal, and mental symptoms make differentiation easy. Metachondromatosis may be mistaken for HME. ${ }^{20}$ The main features are exostoses, primarily in the hands and feet, and enchondromata in the ends of long bones and iliac crests. Most regress spontaneously. Dysplasia epiphysealis hemimelica is a non-hereditary developmental disorder of childhood, characterised by cartilaginous overgrowth of the epiphyses of the carpal or tarsal bones, mostly in a single extremity. ${ }^{28}$ Microscopically the lesions are indistinguishable from HME, but otherwise the differences are obvious. There are numerous other entities in which exostoses may be found. ${ }^{29-45}$

\section{Pathology and pathogenesis}

Exostoses are covered by thickened periosteum that closely adheres to the cartilaginous cap. In children the cap is prominent and surmounts a thin cortex. Some areas of cartilage may have the appearance of an epiphyseal growth plate. Beneath this, spongy bone forms the bulk of the lesion. With aging, the cartilaginous cap ossifies and becomes thinned to a narrow lining or even disappears locally. ${ }^{5713}$ The marrow cavity of exostoses is continuous with the cavity of the underlying bone. Microscopically, in young patients, the cartilage tissue consists of chondroid basal substance with chrondrocytes lined up in columns. ${ }^{5}$ Later on, the organisation of the chondrocytes is less strict. The spongy bone often consists of an irregularly organised trabecular network.

Exostoses are found especially at the site of tendinous insertions of major muscles. In animal experiments it has been shown that functional inactivation of muscles by transsection may prevent formation of exostoses. ${ }^{46}$ This may indicate that muscle tension can be a secondary factor in the pathogenesis of HME. The primary factor remains uncertain, although numerous theories exist. ${ }^{21}$ Mutation(s) in a gene that controls proliferation and differentiation of chondroblasts, which may lead to malignant degeneration under the influence of a second 'hit', seems the most plausible explanation at present.

\section{Genetics}

HME follows an autosomal dominant mode of inheritance. About 60 to $70 \%$ of the patients have a positive family history. ${ }^{581516}$ The mutation rate has been calculated to be $9 \cdot 1 \times 10^{-6.47}$ Sugiura et $\mathrm{al}^{13}$ estimated the penetrance to be $0 \cdot 667$. This reduced penetrance was calculated on the presence of four families with more than one affected child born of apparently unaffected parents. However, in none of these families were both parents fully investigated, including radiography, which leaves this reduction in penetrance unproven. Other authors were unable to find non-penetrance if parents were fully investigated ${ }^{8}$ (personal observations).

There are several reports that mention a preponderance of affected males. ${ }^{5} 1648$ Others have reported an equal sex distribution. ${ }^{815} 21$ One of the main explanations for this distorted sex ratio is probably the diminished expression in a minority of females. ${ }^{12} 21$ The equal expression found by Solomon ${ }^{7}$ and Sugiura $e t a^{13}$ may be at least partly caused by their source of patients, that is, tertiary orthopaedic clinics. Jaffe ${ }^{5}$ reported on the increase in affected offspring in the course of successive male transmissions. This may point to some influencing mechanism, for instance, imprinting. ${ }^{49}$ Anticipation was not detected. ${ }^{813}$ To investigate this further, all published families were gathered in which the diagnosis was reliable, and for which full information on both affected and unaffected family members was given. These data were pooled together with our own data and analysed further (table 2). Affected fathers had more affected than unaffected offspring (99:67) while in affected mothers this ratio was about equal (79:61). This difference, however, was caused by only a few families in which a remarkable male preponderance was found ${ }^{15} 50$ (personal observations). It seems probable that in most families the sex distribution is equal, but that in a minority of families some additional influence is operating. This needs further clarification.

Chromosome studies, both in horses and man, 105152 and DNA polymorphism analysis in horses, ${ }^{53}$ have been inconclusive until now. Buhler and Malik ${ }^{54}$ have suggested that the mutation of HME may be sited in the region 8q23-8q24.1, closely linked to the locus for trichorhinophalangeal syndrome (TRP) type I. They stated that TRP types I and II are possibly not separate entities, but that in TRP type II the deletion is larger and also involves the locus for HME. This theory was recently supported by the description of a patient with TRP type I and 8q deletion. ${ }^{55}$ It is of interest to note that in TRP type II the deletion of $8 \mathrm{q}$ was found to be of maternal origin. ${ }^{56}$ Restriction fragment length polymorphism analysis in man is at

Table 2 Affected and unaffected offspring of 80 nuclear families with $H M E$.

\begin{tabular}{lcc}
\hline & $\begin{array}{c}\text { Affected } \\
\text { fathers }\end{array}$ & $\begin{array}{c}\text { Affected } \\
\text { mothers }\end{array}$ \\
\hline Affected sons & 57 & 46 \\
Unaffected sons & 27 & 18 \\
Affected daughters & 42 & 33 \\
Unaffected daughters & 40 & 43 \\
\hline
\end{tabular}


present being performed in Salt Lake City (Dr K Ward) and Essen (Dr B Horsthemke). They have identified 14 polymorphic probes for the region 8q23-8q24.1 (Horsthemke, personal communication). Linkage analysis has not yet been conclusive, but hopefully may allow firm conclusions in the not too distant future.

I would like to thank Dr B Horsthemke (Essen) for information about the linkage analysis and Dr F A Beemer (Utrecht) for allowing the use of some of his patient data.

1 Hunter J. In: Palmer JF, ed. The works of John Hunter, F.R.S. Vol 1. London: Longman, Rees, Orne, Brown, Green, and Longman, 1835.

2 Boyer A. Traite des maladies chirurgicales. Vol 3. Paris: Ve Migneret, 1814.

3 Virchow R. Ueber the Entstehung des Enchondroms und seine Beziehungen zur Enchondrosis und Exostosis cartilaginea. Monatsberichte der Koniglichen Preussischen Akademie der Wissenschafien 1876:760.

4 Keith A. Studies on the anatomical changes which accompany certain growth-disorders of the human body. I Anat 1920;54: $101-15$.

5 Jaffe HL. Hereditary multiple exostosis. Arch Pathol 1943;36: 335-57.

6 Solomon L. Bone growth in diaphyseal aclasis. $f$ Bone foint Surg (Br) 1961;43:700-16.

7 Solomon L. Hereditary multiple exostosis. F Bone foint Surg (Br) 1963;45:292-304.

8 Solomon L. Hereditary multiple exostosis. Am f Hum Genet 1964;16:351-63.

9 Shapiro F, Simon S, Glimcher MJ. Hereditary multiple exostoses. F Bone foint Surg (Am) 1979;61:815-24.

10 Shupe JL, Leone NC, Olson AE, Gardner EJ. Hereditary multiple exostosis: clinicopathologic features of a comparative study in horses and man. Am $\mathcal{F}$ Vet Res 1979;40:751-7.

11 Li JKK, Moloney BK, Shupe JL, Gardner EJ, Leone NC, Elsner Y. DNA polymorphism analysis of hereditary multiple exostoses in horses. Am $\mathcal{F}$ Vet Res 1989;50:978-83.

12 Krooth RS, Macklin MT, Hilbish TF. Diaphyseal aclasis (multiple exostoses) on Guam. Am $\mathcal{f}$ Hum Genet 1961;13:340-7.

13 Sugiura Y, Sugiura I, Iwata H. Hereditary multiple exostosis: diaphyseal aclasis. fpn f Hum Genet 1976;21:149-67.

14 Voutsinas $S$, Wynne-Davies $R$. The infrequency of malignant disease in diaphyseal aclasis and neurofibromatosis. $\mathcal{f}$ Med Genet 1983;20:345-9.

15 Leone NC, Shupe JL, Gardner EJ, Millar EA, Olson AE, Phillips EC. Hereditary multiple exostosis. A comparative humanequine-epidemiologic study. 7 Hered 1987;78:171-7.

16 Canella P, Gardini F, Boriani S. Exostosis: development, evolution and relationship to malignant degeneration. Ital $\mathcal{f}$ Orthop Traumatol 1981;7:293-8.

17 Gould EA. Three generations of exostoses of the heel. Inherited from father to son. $\mathcal{F}$ Hered 1942;33:228.

18 Callan JE, Wood VE. Spontaneous resolution of an osteochondroma. $\mathcal{Y}$ Bone foint Surg (Am) 1975;57:723.

19 Copeland RL, Meehan PL, Morrissy RT. Spontaneous regression of osteochondromas. F Bone foint Surg (Am) 1985;67:971-3.

20 Kennedy LA. Metachondromatosis. Radiology 1983;148:117-8.

21 Peterson HA. Multiple hereditary osteochondromata. Clin Orthop 1989;239:222-30.

22 Wood VE, Sauser D, Mudge D. The treatment of hereditary multiple exostosis of the upper extremity. $\mathcal{f}$ Hand Surg 1985;10:505-13.

23 Buur T, Morch MM. Hereditary multiple exostoses with spinal cord compression. F Neurol Neurosurg Psychiatry 1983;40:96-8.

24 Chiurco AA. Multiple exostoses of bone with fatal spinal cord compression. Report of a case and brief review of the literature. Neurology 1970;20:275-8.

25 Hershey SL, Lansden FT. Osteochondromas as a cause of false popliteal aneurysms. F Bone foint Surg (Am) 1972;54:1765-8.

26 Ochsner PE. Zum Problem der neoplastischen Entartung bei multipen kartilaginaren Exostosen. Z Orthop 1978;116:369-78.

27 Langer LO, Krassikoff N, Laxova R, et al. The tricho-rhinophalangeal syndrome with exostoses (or Langer-Giedion syndrome): four additional patients without mental retardation and review of the literature. Am $\mathcal{F}$ Med Genet 1984;19:81-111.

28 Kettelkamp DB, Campbell CJ, Bonfiglio M. Dysplasia epiphy. sealis hemimelica. A report of fifteen cases and a review of the literature. F Bone foint Surg (Am) 1966;48:746-6.

29 Beighton P, Learmonth ID. Namaqualand hip dysplasia: an autosomal dominant entity. Am $\mathcal{Y}$ Med Genet 1984;19:161-9.

30 Beighton P, Winship I. Diaphyseal aclasis and achondroplasia: an autonomous entity? Proc Greenwood Genet Center 1990;9: 128-30.

31 Cohen MM, Ruvalcaba RHA, Graham CB. Case report 16. Syndr Ident 1974;2:14-17.

32 Fuchs GA. Multiple cartilaginous exostoses with polyposis of the stomach and colon: a new, hereditary combination differen from Gardner's syndrome. Disch Med Wochenschr 1975;100: 2316-9.

33 Goodman RM, Lewithal I, Solomon A, Klein D. Upper limb involvement in the Klein-Waardenburg syndrome. Am $\mathcal{f}$ Med Genet 1982;11:425-33.

34 Gorlin RJ, Winter RB. Frontometaphyseal dysplasia-evidence for X-linked inheritance. Am $\mathcal{F}$ Med Genet 1980;5:81-4.

35 Kozlowski KS, Celermajer JM, Tink AR. Humero-spinal dysostosis with congenital heart disease. Am $\mathcal{F}$ Dis Child 1974;127: 407-10.

36 Loomer RL. Shoulder girdle dysplasia associated with nail-patella syndrome. Clin Orthop 1989;238:112-6.

37 Mollica F, Li Volti S, Guarneri B. New syndrome: exostoses, anetodermia, brachydactyly. Am $\mathcal{F}$ Med Genet 1984;19:665-7.

38 Pascual-Castroviejo I, Santolaya JM. Cerebro-facio-thoracic dysplasia: report of three cases. Dev Med Child Neurol 1975;17:343-51.

39 Pasma A, Wildervanck LS. Hereditary occurrence of congenital rigidity of the elbows and knees (congenital multiple 'pseudarthrogryposis'). Arch Chir Neerl 1956;8:43-56.

40 Proschek R, Labelle H, Bard C, Marton D. Osteomesopyknosis. F Bone foint Surg (Am) 1985;67:652-3.

41 Reimao R, Diament A. Periodic hypersomnia, congenital ectodermal disorders and multiple exostosis. Arq Neuropsiquiatr 1989;47:76-9.

42 Schiel W, Stengel-Rutkowski S, Schimanek P, Zorn-Bopp E, Bock K. Nonchromosomal dysmorphic syndromes. 2. Craniofacial and skeletal anomalies in two similarly affected mentally retarded sibs. Dysmorphol Clin Genet 1987;1:109-21.

43 Schweitzer G, Jones B, Timme A. Upington disease: a familial dyschondroplasia. S A Med f 1971;45:994-1000.

44 Stoll CG, Collin D, Dreyfus J. Osteomesopyknosis: an autosomal dominant osteosclerosis. Am $\mathcal{F}$ Med Genet 1981;8:349-53.

45 Thanos C, Stewart RE, Zonana J. Craniosynostosis, bony exostoses, epibulbar dermoids, epidermal nevus and slow development. Syndr Ident 1977;5:19-21.

46 Hamre CJ, Yeager VL. Influence of denervated muscles on exostoses of rats fed a sweet pea diet. Arch Pathol 1958;65: 215-27.

47 Murken JD. Zur Mutationsrate des Gens fur multiple cartilaginare Exostosen, ein Beitrag zur Spontansmutationsrate menschlicher Gene. Naturwissenschaften 1963;50:104.

48 Harris H. A sex-limiting gene in diaphyseal aclasis (multiple exostoses). Ann Eugen 1948;14:165-70.

49 Hall JG. Genomic imprinting: review and relevance to human diseases. Am 7 Hum Genet 1990;46:857-73.

50 Bennett GE, Berkheimer GA. Malignant degeneration in a case of multiple benign exostoses. Surgery 1941;10:781-92.

51 Gardner EJ, Shupe JL, Leone NC, Olson AE. Hereditary multiple exostosis. A comparative genetic evaluation in man and horses. $\mathcal{F}$ Hered 1975;66:318-22.

52 Hall JG, Wilson RD, Kalousek D, Beauchamp R. Familial multiple exostoses-no chromosome 8 deletion observed. Am $\mathcal{J}$ Med Genet 1985;22:639-40.

$53 \mathrm{Li}$ JKK, Moloney BK, Shupe JL, Gardner EJ, Leone NC, Elsner Y. DNA polymorphism analysis of hereditary multiple exostoses in horses. Am J Vet Res 1989;50:978-83.

54 Buhler EM, Malik NJ. The trichorhinophalangeal syndrome(s): chromosome 8 long arm deletion: is there a shortest region of overlap between reported cases? TRP I and TRP II syndromes: are they separate entities? Am $\mathcal{F}$ Med Genet 1984;19:113-9.

55 Hamers A, Jongbloet P, Peeters G, Fryns JP, Geraedts J. Severe mental retardation in a patient with tricho-rhino-phalangeal syndrome type I and 8q deletion. Eur $\mathcal{F}$ Pediatr 1990;179: 618-20.

56 Ludecke HJ, Burdiek R, Senger G, Claussen U, Passarge E, Horsthemke B. Maternal origin of a de novo chromosome 8 deletion in a patient with Langer-Giedion syndrome. Hum Genet 1989;82:327-9. 